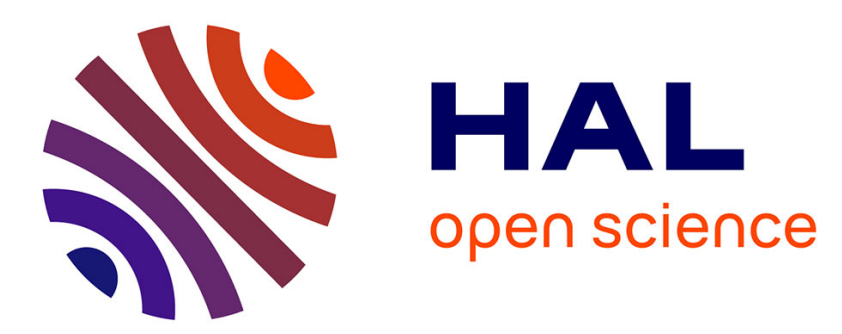

\title{
Synthetic wastewaters treatment by electrocoagulation to remove silver nanoparticles produced by different routes
}

\author{
M. S. Matias, S. P. Melegari, D. S. Vicentini, W. G. Matias, C. Ricordel, D
} Hauchard

\section{To cite this version:}

M. S. Matias, S. P. Melegari, D. S. Vicentini, W. G. Matias, C. Ricordel, et al.. Synthetic wastewaters treatment by electrocoagulation to remove silver nanoparticles produced by different routes. Journal of Environmental Management, 2015, 159, pp.147-157. 10.1016/j.jenvman.2015.05.006 . hal-01162338

\section{HAL Id: hal-01162338 \\ https://hal-univ-rennes1.archives-ouvertes.fr/hal-01162338}

Submitted on 19 Jun 2015

HAL is a multi-disciplinary open access archive for the deposit and dissemination of scientific research documents, whether they are published or not. The documents may come from teaching and research institutions in France or abroad, or from public or private research centers.
L'archive ouverte pluridisciplinaire HAL, est destinée au dépôt et à la diffusion de documents scientifiques de niveau recherche, publiés ou non, émanant des établissements d'enseignement et de recherche français ou étrangers, des laboratoires publics ou privés. 


\title{
SYNTHETIC WASTEWATERS TREATMENT BY ELECTROCOAGULATION TO REMOVE SILVER NANOPARTICLES PRODUCED BY DIFFERENT ROUTES
}

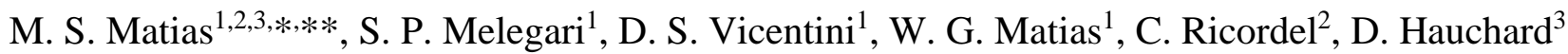

${ }^{1}$ Department of Sanitation and Environmental Engineering, Federal University of Santa Catarina (Universidade Federal de Santa Catarina), Florianópolis, Brazil.

${ }^{2}$ Équipe Recherche de l'Ecole des Métiers de l'Environnement. Ecole des Metiers de l'Environnement, Bruz, France.

${ }^{3}$ Équipe de Recherche Chimie et Ingénierie des Procédés. École Nationale Supérieure de Chimie de Rennes, Rennes, France.

*Corresponding author. Équipe de Recherche Chimie et Ingénierie des Procédés, École Nationale Supérieure de Chimie de Rennes, Rennes 35708, France. Tel.: +33 02232380 12; fax: +33 02232381 11. E-mail address: msmatias.esa@gmail.com (M. S. Matias).

**Permanent address. Departamento de Engenharia Sanitária e Ambiental, Universidade Federal de Santa Catarina, Florianópolis, SC, CEP 88.040-900, Brazil. Tel.: +55 483721 77 41; fax: +55 4837219823. E-mail address: msmatias.esa@gmail.com (M. S. Matias).

\begin{abstract}
Nanoscience is a field that has stood out in recent years. The accurate long-term health and environmental risks associated with these emerging materials are unknown. Therefore, this work investigated how to eliminate silver nanoparticles (AgNPs) from synthetic effluents by electrocoagulation (EC) due to the widespread use of this type of nanoparticle (NP) in industry and its potential inhibition power over microorganisms responsible for biological treatment in effluent treatment plants. Synthesized AgNPs were studied via four different routes by chemical reduction in aqueous solutions to simulate the chemical variations of a hypothetical industrial effluent, and efficiency conditions of the EC treatment were determined. All routes used silver nitrate as the source of silver ions, and two synthesis routes were studied with sodium citrate as a stabilizer. In route I, sodium citrate functioned simultaneously as the reducing agent and stabilizing agent, whereas route II used sodium borohydride as a reducing agent. Route III used D-glucose as the reducing agent and sodium pyrophosphate as the stabilizer; route IV used sodium pyrophosphate as the stabilizing agent and sodium borohydride as the reducing agent. The efficiency of the EC process of the different synthesized solutions was studied. For route I, after 85 minutes of treatment, a significant decrease in the plasmon resonance peak of the sample was observed, which reflects the efficiency in the mass reduction of AgNPs in the solution by $98.6 \%$. In route II, after 12 minutes of EC, the absorbance results reached the detection limit of the measurement instrument, which indicates a minimum reduction of $99.9 \%$ of AgNPs in the solution. During the 4 minutes of treatment in route III, the absorbance intensities again reached the detection limit, which indicates a minimum reduction of $99.8 \%$. In route IV, after 10 minutes of treatment, a minimum AgNP reduction of 99.9\% was observed. Based on these results, it was possible to verify that the solutions containing citrate considerably increased the necessary times required to eliminate AgNPs from the synthesized effluent, whereas solutions free of this reagent showed better results on floc formation and, therefore, are best for the treatment. The elimination of AgNPs from effluents by EC proved effective for the studied routes.
\end{abstract}

Keywords: Wastewater treatment; Silver nanoparticles; Electrocoagulation. 


\section{Highlights:}

Different synthesis routes of AgNPs were accomplished and characterized

Solutions with sodium citrate increase the time required to eliminate AgNPs by EC

Electrocoagulation showed able to remove AgNPs from the solution. 
Nanotechnology has opened many possibilities for the industrial sector that is used to develop applied technologies, which includes environment protection. At the nanometer scale, materials and systems can reveal completely new features, which significantly modify their properties and their associated physical, chemical, and biological phenomena and processes. The changes are so fundamental that the material properties at the nanometer level cannot be surmised from those at a conventional scale (DUQUET, et al., 2006)

Despite their benefits, nanoparticles (NPs) can exhibit toxic characteristics and can be more easily absorbed by living organisms (DUQUET, et al., 2006). Thus, NP properties foster the need to study the identification, evaluation, and management of the risks that may arise from their creation and until their elimination. It is estimated that the environmental risks of emerging nanomaterials is high (SELLERS, et al., 2009).

Silver nanoparticles (AgNPs), which are also called colloidal silver (NETO, et al., 2010), have been used in increasing amounts in industry due to their bactericidal power. In this context, two points are raised regarding the use of AgNPs: concern over their potential risk due to their high exposure to the environment (CUMBERLAND \& LEAD, 2009) and the risk of their presence in effluent treatment stations (HOU, et al., 2013) (YANG, et al., 2014) (KAEGI, et al., 2011) because microbiological dysfunction can result in a loss of efficiency, particularly in anoxic treatments (CHOI, et al., 2008). Because of their potential harmful effects (JEONG, et al., 2014) (KHEYBARI, et al., 2010), means of their disposal and treatment must be developed and studied to ensure the stability of the ecosystem.

Several wastewater treatment technologies have been developed to accelerate the natural process of elimination of classical pollutants, which essentially consist of biological and physicochemical processes. In this sense, currently, it is interesting to verify the applicability and efficiency of the current processes of wastewater treatment to effluents containing NPs in solutions. With the knowledge of the potential use of coagulation and flocculation techniques in this field (SUN, et al., 2013) and in addition to alternative techniques (KHAN, et al., 2012), electrocoagulation (EC) has become the object of study and analysis in removing these emerging materials. EC presents certain advantages over the traditional process: reduced detention times, less sludge production, and the non-necessity of dosing equipment; its primary advantage in eliminating small colloidal particles is due to the electrical field generated during this process (BARBOSA \& TERAN, 2009).

EC is a electrochemical process that consisting in a set of phenomena associated with the production of electric charge transfer through an interface formed by contact between the electrode (metal, graphite, etc.) and the electrolyte (conductor by ion migration of electrons in place: ionic aqueous or nonaqueous solutions, ionized salts, some ionic solids). This contact is referred to as electrochemical surface, which produces a transfer of charges, which corresponds to the passage of an electric current, having as its main effect a chemical transformation called electrochemical reaction (or electrode reaction). Redox reactions that occurs on process of EC involves the generation of coagulants in situ by electrolytic oxidation sacrificial electrode (BARBOSA \& TERAN, 2009). The materials used are usually aluminum ( $\mathrm{Al})$ or iron $(\mathrm{Fe})$, where the electrodes can be made of plates of these materials, or fragments. The selection of materials is very important, and the most commonly used in the EC of iron or aluminum, as they are cheap and easily available (SILVA, 2009).

EC of effluent using aluminum electrodes has been successfully applied to remove, between other pollutants, the heavy metals (HEIDMANN \& CALMANO, 2008) (KHANDEGAR \& SAROHA, 2013) (LU, et al., 2015). After the dissolution of some aluminum species may be formed, depending on the solution $\mathrm{pH}$. The redox reactions involve are as follows (SILVA, 2009):

Anode:

$\left.\mathrm{Al}_{(\mathrm{s})} \rightarrow \mathrm{Al}_{(\mathrm{aq})}\right)^{3+}+3 \mathrm{e}^{-}$

$2 \mathrm{H}_{2} \mathrm{O}_{(\mathrm{l})} \rightarrow \mathrm{O}_{2(\mathrm{~g})}+4 \mathrm{H}^{+}(\mathrm{aq})+4 \mathrm{e}^{-}$

Cathode:

$2 \mathrm{H}^{+}{ }_{(\mathrm{aq})}+2 \mathrm{e}^{-} \rightarrow \mathrm{H}_{2(\mathrm{~g})}$

$2 \mathrm{H}_{2} \mathrm{O}_{(\mathrm{l})}+2 \mathrm{e}^{-} \rightarrow \mathrm{H}_{2(\mathrm{~g})}+2 \mathrm{OH}^{-}$

General redox reaction:

$2 \mathrm{Al}_{(\mathrm{s})}+6 \mathrm{H}_{2} \mathrm{O}+2 \mathrm{OH}^{-} \rightarrow 2 \mathrm{Al}(\mathrm{OH})_{4}^{-} \downarrow+3 \mathrm{H}_{2}(\mathrm{~g})$ 
Figure 1 shows a summary of key redox reactions presented in respect to aluminum electrode.

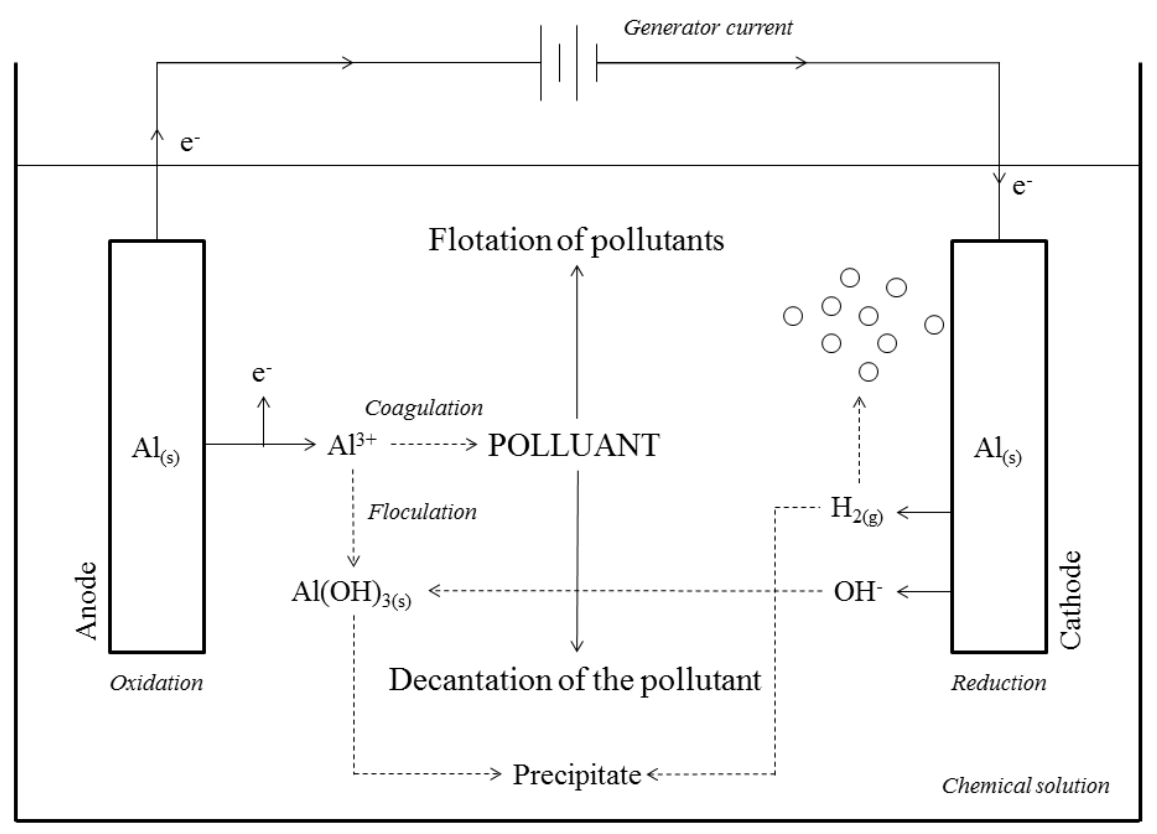

Figure 1: Scheme of the batch cell of EC using Al electrodes and some basic processes involved.

The $\mathrm{pH}$ in the $\mathrm{EC}$ is of fundamental importance and as its variation determine the reactions involved in this process (SILVA, 2009). The increase of $\mathrm{pH}$ will increase the amount of aluminum hydroxide complexes on the media, following the reactions:

$$
\begin{aligned}
& \mathrm{Al}^{3+}+\mathrm{H}_{2} \mathrm{O} \rightarrow \mathrm{AlOH}^{2+}+\mathrm{H}^{+} \\
& \mathrm{AlOH}^{2+}+\mathrm{H}_{2} \mathrm{O} \rightarrow \mathrm{Al}(\mathrm{OH})_{2}++\mathrm{H}^{+} \\
& \mathrm{Al}(\mathrm{OH})_{2}{ }^{+}+\mathrm{H}_{2} \mathrm{O} \rightarrow \mathrm{Al}(\mathrm{OH})_{3}+\mathrm{H}^{+} \\
& \mathrm{Al}(\mathrm{OH})_{3}+\mathrm{H}_{2} \mathrm{O} \rightarrow \mathrm{Al}(\mathrm{OH})_{4}+\mathrm{H}^{+} \\
& 2 \mathrm{H}_{2} \mathrm{O} \rightarrow \mathrm{O}_{2(\mathrm{~g})}+4 \mathrm{H}^{+}(\mathrm{aq})+4 \mathrm{e}^{-} \\
& \text {n } \mathrm{Al}(\mathrm{OH})_{3} \rightarrow \mathrm{Al}_{\mathrm{n}}(\mathrm{OH})_{3 \mathrm{n}}
\end{aligned}
$$

Such cationic hydroxides complexes $\left(\mathrm{Al}_{\mathrm{n}}(\mathrm{OH})_{3 n}\right)$ can effectively remove pollutants by adsorption and neutralizing the surface charge thereof, forming flocs (MOLLAH, et al., 2001). The efficient of EC technique is due these flocs present a higher surface area of adsorption when metal hydroxides are used as coagulant (MOLLAH, et al., 2001)

This work studied the removal of AgNPs in solutions by EC with aluminum electrodes, which is a electrochemical process that forms flocs of a metallic hydroxide in an effluent (flocculating agent) by electrodissolution of a soluble anode. Four different synthesis routes of AgNPs by chemical reduction of silver salts through reducing agents (bottom-up process) were developed, which includes emerging biosynthetic methods with natural reducers (polysaccharides) (KHOLOUD, et al., 2010), to simulate several hypothetical industrial effluents with different physicochemical properties. Additionally, the efficiency of the treatment by EC for each route was studied under different electrochemical parameters using a complete mix reactor operating in batches.

\section{Materials and methods}

\section{$2.1 \quad$ Materials}

The reagents used in the synthesis of AgNPs were sodium citrate dihydrate $\left(\mathrm{Na}_{3} \mathrm{C}_{6} \mathrm{H}_{5} \mathrm{O}_{7} .2 \mathrm{H}_{2} \mathrm{O}\right.$; purity $\geq 99.0 \%$, Fluka Chemika), silver nitrate $\left(\mathrm{AgNO}_{3}\right.$, purity $\geq 99.8 \%$, Riedel-de Haën), sodium borohydride $\left(\mathrm{NaBH}_{4}\right.$; purity $\geq 98.0 \%$, Aldrich), sodium pyrophosphate decahydrate $\left(\mathrm{Na}_{4} \mathrm{P}_{2} \mathrm{O}_{7} .10 \mathrm{H}_{2} \mathrm{O}\right.$; purity $\geq 99.0 \%$, Aldrich), D-glucose $\left(\mathrm{C}_{6} \mathrm{H}_{12} \mathrm{O}_{6}\right.$; Janssen Chimica), and ultrapure water. 


\subsection{Synthesis of AgNPs}

The AgNPs were synthesized using four different routes, which all used $\mathrm{AgNO}_{3}$ as the source of silver. Route I was based on the classical method by Turkevich (KRUTYAKOV, et al., 2008), which used sodium citrate simultaneously as the reducing agent and stabilizer. The reagents $\mathrm{AgNO}_{3}$ and $\mathrm{Na}_{3} \mathrm{C}_{6} \mathrm{H}_{5} \mathrm{O}_{7}$ were added to a flask containing ultrapure water, which was heated at $70^{\circ} \mathrm{C}$ for $2 \mathrm{~h}$ with continuous stirring. The solution was cooled by immersion in water at room temperature. Route II used $\mathrm{Na}_{3} \mathrm{C}_{6} \mathrm{H}_{5} \mathrm{O}_{7}$ as the stabilizing agent and $\mathrm{NaBH}_{4}$ as the reducing agent (PINTO, et al., 2010). $\mathrm{AgNO}_{3}$ and $\mathrm{Na}_{3} \mathrm{C}_{6} \mathrm{H}_{5} \mathrm{O}_{7}$ were added to a flask containing ultrapure water and was continuously stirred for 60 seconds at room temperature. $\mathrm{NaBH}_{4}$ was then added, and the solution was continuously stirred for an additional 60 seconds. For route III, the reducing agent was D-Glucose (SHI, et al., 2011), and the stabilizing agent was sodium pyrophosphate; the solution containing $\mathrm{AgNO}_{3}, \mathrm{Na}_{4} \mathrm{P}_{2} \mathrm{O}_{7} .10 \mathrm{H}_{2} \mathrm{O}$ and D-glucose was continuously stirred and heated to $90^{\circ} \mathrm{C}$ for $1 \mathrm{~h}$ and $30 \mathrm{~min}$. At the end, the solution was cooled by immersion in water at room temperature. In route $\mathrm{IV}$, the reducing agent was $\mathrm{NaBH}_{4} ; \mathrm{AgNO}_{3}$ and $\mathrm{Na}_{4} \mathrm{P}_{2} \mathrm{O}_{7} .10\left(\mathrm{H}_{2} \mathrm{O}\right)$ were added to ultrapure water, and the solution was continuously stirred at room temperature for 60 seconds. $\mathrm{NaBH}_{4}$ was then added, and the solution was stirred for 30 seconds. The $\mathrm{AgNO}_{3}$ concentrations and the reducing and stabilizing agents used in each route are shown in Table 1. All syntheses were performed in the absence of light. The synthesized solutions of AgNPs were stored under refrigeration at $4{ }^{\circ} \mathrm{C}$ and were protected from light.

Table 1: Concentrations of reagents used in the four synthetic routes.

\begin{tabular}{ccccc}
\hline Reagents & Route I & Route II & Route III & Route IV \\
\hline \multirow{2}{*}{ Reducing Agent } & $\mathrm{Na}_{3} \mathrm{C}_{6} \mathrm{H}_{5} \mathrm{O}_{7}$ & $\mathrm{NaBH}_{4}$ & $\mathrm{C}_{6} \mathrm{H}_{12} \mathrm{O}_{6}$ & $\mathrm{NaBH}_{4}$ \\
& $3 m M$ & $0.02 \mathrm{mM}$ & $1.6 \mathrm{mM}$ & $0.01 \mathrm{mM}$ \\
\cline { 3 - 5 } & $3 \mathrm{ma} \mathrm{C}_{6} \mathrm{H}_{5} \mathrm{O}_{7}$ & $\mathrm{Na}_{4} \mathrm{P}_{2} \mathrm{O}_{7}$ & $\mathrm{Na}_{4} \mathrm{P}_{2} \mathrm{O}_{7}$ \\
\multirow{2}{*}{ Stabilizing Agent } & & $0.25 \mathrm{mM}$ & $0.025 \mathrm{mM}$ & $0.20 \mathrm{mM}$ \\
\hline \multirow{2}{*}{$\boldsymbol{A g N \boldsymbol { O O } _ { 3 }}$} & & $0.25 \mathrm{mM}$ & $0.4 \mathrm{mM}$ & $0.25 \mathrm{mM}$ \\
\hline
\end{tabular}

\subsection{Characterization}

The methods used to characterize the dispersions of AgNPs and the synthesized solutions were both qualitative and quantitative. The decrease in concentration of AgNPs was quantified in the solution by UV/Vis spectroscopy through the relative analysis of the absorbance before and after the EC treatment. In this research, a Lambda 35 (Perkin Elmer) UV/Vis scanning spectrometer was used, and the cuvettes that were used were all made of quartz to ensure an accurate spectral analysis. The hydrodynamic diameter size distribution of the agglomerates of AgNPs in the solution was evaluated by dynamic diffusion of light of each synthesized route. To apply this method, a Delsa ${ }^{\mathrm{TM}}$ Nano (Beckman Coulter) was used. The same method allowed the polydispersity index (PI) to be determined, which is a parameter that expresses the tendency toward homogeneity or heterogeneity in the size distribution of the NPs. With a ZetaSizer Nano-ZS (Malvern Instruments), the surface charge of the synthesized NPs, the zeta potential, was determined, which an essential parameter to estimate the stability (tendency to agglomerate) of the obtained colloidal silver dispersions.

The elementary qualitative relationships of certain results also required analysis by energy dispersive spectrometry (EDS), which was performed in collaboration with the Center for Scanning Electron Microscopy and Microanalysis (CMEBA, Centre de Microscopie Electronique à Balayage et Microanalyse) using a traditional JSM 6400 scanning electron microscope for EDS observations with the help of a LinkINCA OXFORD energy dispersive spectrometer.

With respect to the characterization of the AgNPs solutions, the following parameters were monitored: $\mathrm{pH}$, conductivity, and turbidity. The first two parameters are important in monitoring the physicochemical aspects of the synthesized samples and those subjected to treatment by EC. The device, Seven Multi (Mettler Toledo), allowed simultaneous analysis of $\mathrm{pH}$ and conductivity; Regarding turbidity, turbidity is an expression of the optical property that causes the diffusion and absorption of light rather than its transmission without changing the direction of the light beam through the sample 
(CLESCERI, et al., 1998). This measurement allows estimating the interference, which indicates the presence of other chemical species in the medium other than AgNPs. The device used was a PC compact (Lovibond), which uses the Nephelometric method and expresses the results in NTU (Nephelometric Turbidity Unit).

\subsection{Treatment by EC}

The EC treatment was conducted in a batch reactor under a hydraulic regime with a solution capacity of $250 \mathrm{~mL}$, which maintained the solutions under complete mixing via magnetic stirring. In this system, the electrolytic process was conducted with a pair of aluminum electrodes and a DC generator (MICROLAB Power Supply MX, Micronics-Systems, 600 V - 1A).

The aluminum electrodes (anode and cathode) were each prepared with dimensions of $7.5 \mathrm{~cm}$ in length, $2 \mathrm{~cm}$ in width, and $2 \mathrm{~mm}$ in thickness (dimensions immersed in solution) with a spacing of $2 \mathrm{~cm}$, which was achieved using a wood spacer to ensure the electrical insulation between the cathode and anode. To ensure the conductivity of the samples treated by EC, a standard sodium nitrate concentration $(5 \mathrm{mM})$ was used in all solutions that went through the treatment process. The addition of salt is closely linked to the resistivity of the medium, which directly influences the energy efficiency of the electrochemical process. The conditions of the EC processes, such as time, voltage, and amperage were variable for each synthesized route, which is one of the goals of this study.

After the EC treatment, all samples were centrifuged (Fisher Bioblock Scientific 1-6P, SIGMA) for 20 minutes at $5000 \mathrm{rpm}$ to remove the formed flocs, which ensures the analysis of the supernatant can be performed.

In this regard, it was possible to perform various EC tests using the following treatment efficiency parameters: relative mass removal of NPs from the solution over time by UV/Vis absorption spectrum, energy consumption (Equation 1), and electric current density (Equation 2):

$$
\mathrm{E}(\mathrm{J})=\mathrm{V} \cdot \mathrm{i} \cdot \Delta \mathrm{t}
$$

Equation 1

where $E$ is consumed electrical energy $(J), V$ is voltage $(V), I$ is electric current $(A)$ and $\Delta t$ is time (s).

$$
\mathrm{J}=\mathrm{i} / S_{e}
$$

Equation 2

where $J$ is charge transfer current density $\left(A \cdot \mathrm{m}^{-2}\right)$, i is electric current (A) and $S_{e}$ is electrode surface $\left(\mathrm{m}^{2}\right)$.

The mass consumption of aluminum electrode in an EC process is determining by Faraday's Law (Equation 3), who establishes that the mass consumption of the cathode is directly proportional to the electric current and treatment time.

$$
\mathrm{m}=\frac{\text { i.t.M }}{\text { F.n }}
$$

Equation 3

where $\mathrm{m}$ is the mass of electrode $(\mathrm{g}), \mathrm{i}$ the electric current $(\mathrm{A}), \mathrm{t}$ the electrolysis time (s), $\mathrm{M}$ the specific molecular weight of electrode $\left(\mathrm{g} \cdot \mathrm{mol}^{-1}\right), \mathrm{n}$ is the number of electrons involved in the reaction and $\mathrm{F}$ is the Faraday's constant $\left(96485.34\right.$ C. $\left.\mathrm{mol}^{-1}\right)$.

\section{Results and Discussion}

\subsection{Synthesis and Characterization}

To validate the results obtained throughout the EC treatment, the following primary parameters of the synthesized solutions were monitored: its temporal stability and the relative concentration of NPs. A satisfactory sample was sought for use in the EC tests as follows: a clear solution with minimal presence of turbidity such that the treatment results are directly linked to the presence of NPs using a yellow or orange indicative color (indicative of the presence of AgNPs) and an absorbance peak near $0.5 \mathrm{AU}$ 
(absorbance unit) of approximately $400 \mathrm{~nm}$, such that the values would be close to those found from literature (KHAN, et al., 2011) (CUMBERLAND \& LEAD, 2009) (CHOI, et al., 2008) (KANG, et al., 2011).

Regarding turbidity, this parameter is important because it indicates the presence of non-reduced silver ions, where clear solutions confirm the end of the synthesis reaction (KHEYBARI, et al., 2010). With respect to the absorption band, the $350-600 \mathrm{~nm}$ range is attributed to the surface plasmon resonance by the collective oscillation of free electrons in the conduction band of AgNPs (DENG, et al., 2008). Due to plasmon excitation, certain dispersions of metal NPs show unique bands. Note that the bandwidth is a good indicator of the size of NPs, i.e., as the size of the NPs increases, the peak becomes narrower with an increase in intensity, and the plasmon band narrows (CHOI, et al., 2008). Another important characteristic in the analysis of the UV/Vis spectrum is the number and position of the peaks, which depend on the shape of the particles, where for one elliptical particle, two peaks are identified in one UV/Vis spectrum, whereas spherical silver particles exhibit only one peak (CHOI, et al., 2008). The size of NPs is also linked to the oscillation frequency of the plasmon resonance, i.e., to the dominant wavelength in an UV/Vis spectrum (BONIFÁCIO, 2006). Thus, smaller particles tend to present plasmon resonance peaks with smaller wavelengths compared with that of larger particles. This phenomenon indicates that when a plasmon is formed on a particle, the electron oscillation tends to displace the peak beyond the starting point, which exponentially decays with the distance according to its surface. This oscillation is called the evanescent electric field. If the particles are close enough, the evanescent electric fields can interact with each other, which generates a resonance at lower energy levels (larger wavelengths), resulting in a change in colors and emergence of new absorption bands in the electronic spectra (BONIFÁCIO, 2006). Therefore, this approach can be used for an aggregation of particles, different shapes (spherical, rod, elliptical, etc.), or by simply increasing their concentration in the medium (SOBCZAK-KUPIEC, et al., 2011).

Additionally, the PI of the synthesized solutions was verified, and using this method, it was possible to determine the size distribution pattern of the synthesized NPs with respect to the diffracted signal intensity. Values close to zero indicate a monodispersion (particles with equivalent sizes), whereas high values indicate a tendency towards heterogeneous suspensions. The authors agree that values below 0.2 characterize a suspension trend to monodispersion (CHANDINI, et al., 2013). This parameter is quantified by the result of the hydrodynamic diameter size distribution of the agglomerates of AgNPs in the solution conducted by DLS.

The results shown below confirm and validate the four synthetic routes proposed in this research.

Table 2: Physicochemical characteristics resulting from the synthesis process of AgNPs.

\begin{tabular}{lccccccc}
\hline & pH & PI & Cond. & Turbidity & \multicolumn{2}{c}{ UV-Vis } & Zeta Pot. \\
& & & $(\mu \mathrm{S} / \mathrm{cm})$ & $(N T U)$ & $\lambda_{\max }(\mathrm{nm})$ & $A b s(A U)$ & $(\mathrm{mV})$ \\
\hline Route I & 6.8 & 0.342 & 669.0 & 5.2 & 409 & 0.124 & -45.9 \\
\hline Route II & 6.0 & 0.365 & 72.8 & 4.2 & 389 & 0.445 & -47.3 \\
\hline Route III & 5.7 & 0.312 & 43.1 & 0.5 & 405 & 0.436 & -34.3 \\
\hline Route IV & 8.4 & 0.211 & 77.9 & 0.0 & 402 & 0.912 & -45.0 \\
\hline
\end{tabular}

Route I proved unstable during the 18 days of monitoring (Figure 2A); its plasmon resonance peak progressively changed, which is most likely due to the presence of silver ions (reflected by high turbidity) and its continuous reaction with the excess of sodium citrate throughout the monitored days. However, with regard to the tendency of particle agglomeration, the recorded zeta potential confirms the dispersion stability of $-45.9 \mathrm{mV}$ (Table 2). The stability of particles is confirmed in solutions when the zeta potential is less than $-30 \mathrm{mV}$ or greater than $30 \mathrm{mV}$ (NETO, et al., 2010). In route II, it was possible to achieve, for a molar ratio of 12.5:12.5:1 between silver salt, the stabilizing agent, and the reducing agent, respectively, a reduced turbidity level (Table 2) and a plasmon resonance peak near $0.5 \mathrm{AU}$; these results were satisfactory. The zeta potential recorded for this route was $-47.3 \mathrm{mV}$ (Table 2), which indicates a stable suspension.

Figure 2B shows the temporal stability of the AgNPs synthesized through route II, where the increase in the absorption in the UV/Vis spectrum again indicates a likely presence of silver ions and an excess of sodium citrate in the solution, which leads to the continuous synthesis of NPs with time. The 
presence of a second peak in the region between 460 and $500 \mathrm{~nm}$ after the 10th day is likely indicative of the geometric alteration of the NPs. With a molar ratio of 16:1:64 between the silver salt, stabilizing agent, and reducing agent, respectively, for synthesis route III, its turbidity level and plasmon resonance peak (Table 2) and the suspension stability are satisfactory, which represented by a zeta potential of -34.3 $\mathrm{mV}$ (Table 2). The temporal analysis of this route showed a remarkable stability over 24 days, as shown in Figure 2C.

Finally, in route IV, the sodium borohydride was used as the reducing agent, and sodium pyrophosphate was used as the stabilizing agent, which resulted in significant temporal stability during the 14 days of monitoring, as shown in Figure 2D. A molar ratio of 25:20:1 between the silver salt, stabilizing agent, and the reducing agent, respectively, was used in this route, where the turbidity and absorbance peak showed the best results compared with that of the other developed routes (Table 2). A zeta potential of $-45 \mathrm{mv}$ of this solution again indicated a stable particle suspension (Table 2).

A)

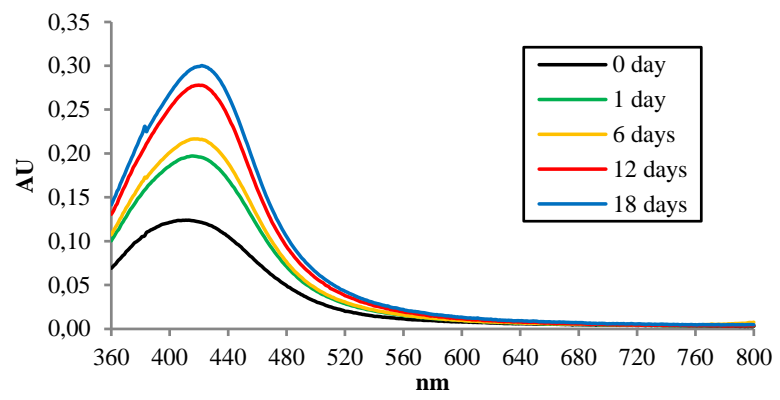

C)

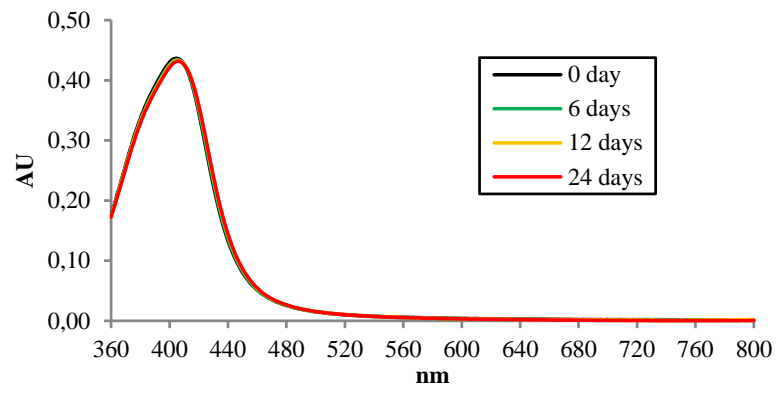

B)

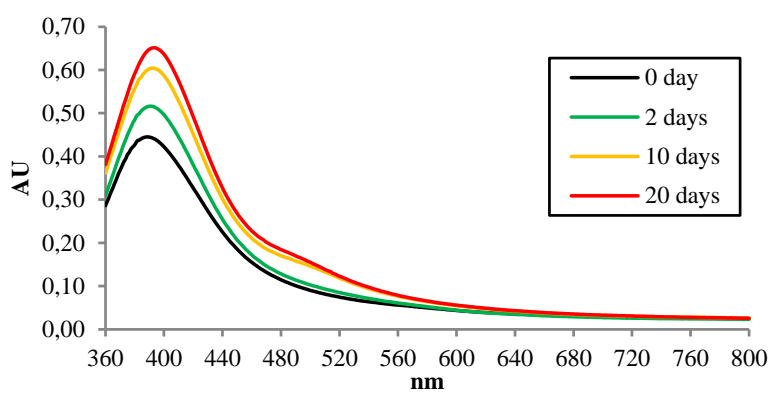

D)

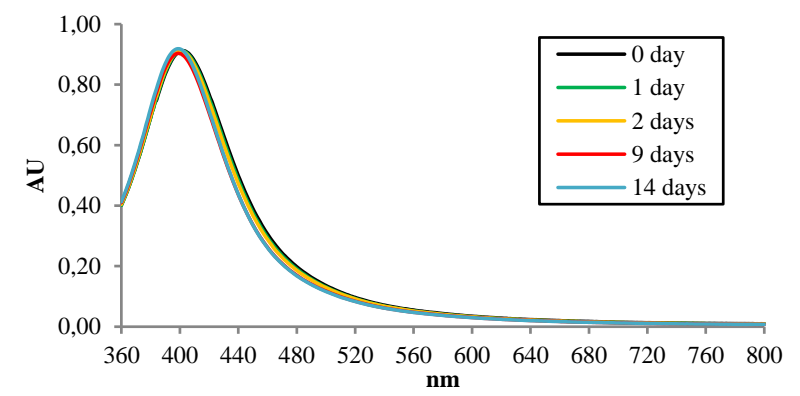

Figure 2: UV/Vis spectra indicating the stability pattern of the solution of AgNPs synthesized through routes I (A), II (B), III, (C) and IV (D).

To confirm the nanometric scale of the synthesized particles, the solutions were characterized using a DLS spectrum, which determines the volumetric ratio between the different hydrodynamic diameters of NPs found in a solution, where an average hydrodynamic diameter of approximately $3 \mathrm{~nm}$ was observed for route I. Using the same method, it is also possible to determine the PI, where a heterogeneous dispersion of 0.342 was obtained for route I (Figure 3A).

The analysis of the suspension in route II had a PI of 0.365 , and the size distribution by volume showed a predominance of NPs with dimensions of less than $5 \mathrm{~nm}$ (Figure 3B), where the average hydrodynamic diameter was approximately $2.5 \mathrm{~nm}$. A PI of 0.312 was found for route III, which indicates a tendency for a heterogeneous suspension, and its volumetric distribution confirmed the predominance of NPs with dimensions of less than $25 \mathrm{~nm}$ (Figure 3C), where its average hydrodynamic diameter was approximately $20 \mathrm{~nm}$.

Finally, with a PI of 0.211 , the size distribution of the NPs in route IV (Figure 3D) was determined by analyzing its volumetric distribution because this method provides the combined particle diameter with the stabilizing agent around the particle. It can be concluded that the developed synthesis resulted in NPs with dimensions predominantly less than $100 \mathrm{~nm}$ with an approximate average hydrodynamic diameter of $50 \mathrm{~nm}$. 
A)

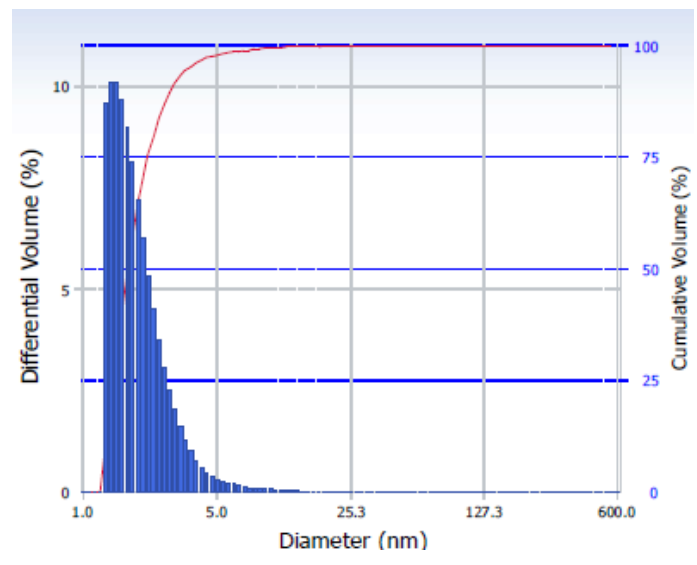

C)

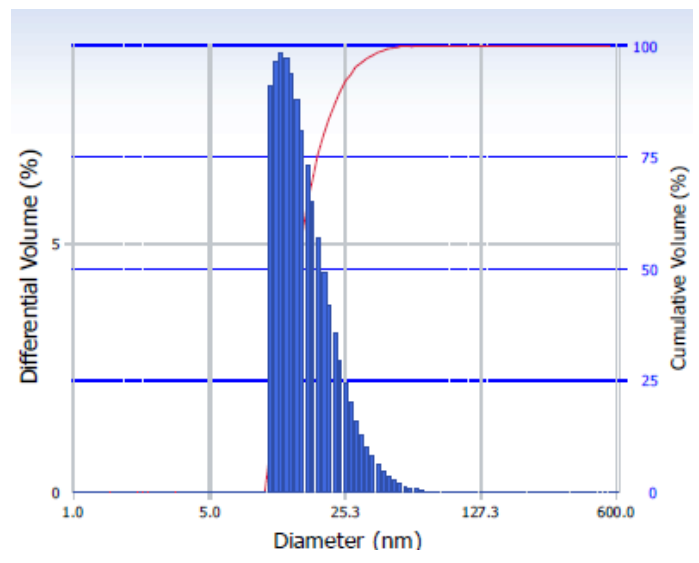

B)

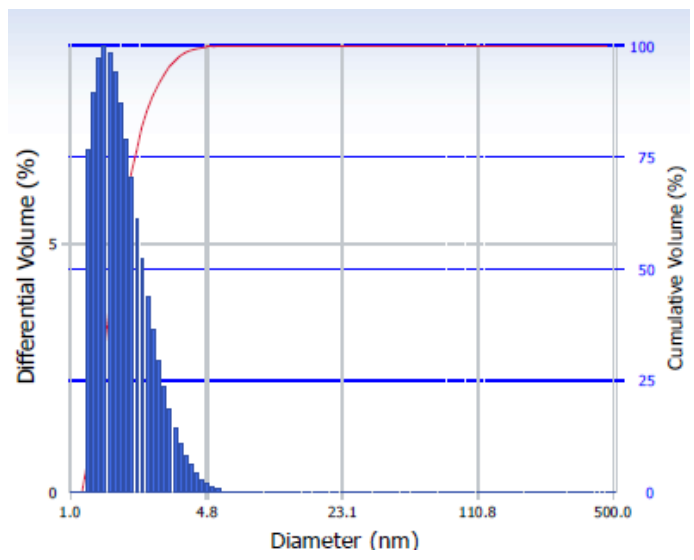

D)

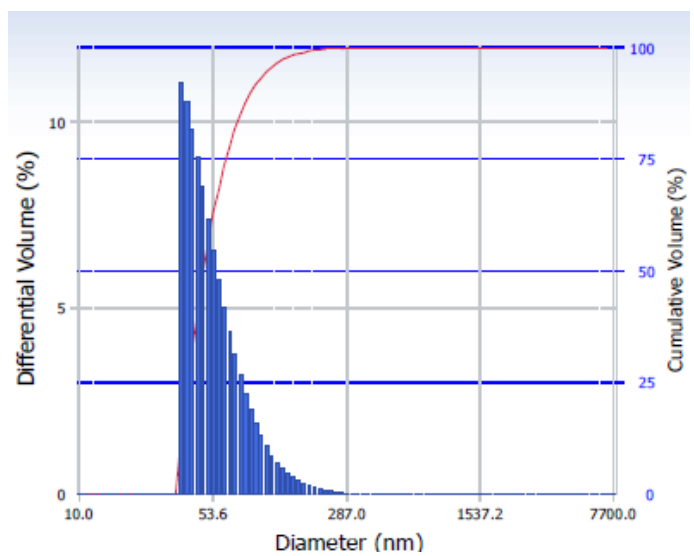

Figure 3: DLS spectrum (volumetric distribution) of the AgNPs synthesized by routes I (A), II (B), III, (C) and IV (D).

The colorimetric results of the four discussed synthesis routes are shown in Figure 4. The predominance of yellow in routes I, II, and III can be observed, which indicates the formation of AgNPs (SOBCZAK-KUPIEC, et al., 2011). The color of route IV is more orange due to the high UV/Vis absorption peak and, consequently, to a high concentration of AgNPs. The change in color of the samples is linked, among other factors, to the increase in concentration of AgNPs of the same size, i.e., the increase in concentration of AgNPs of similar size (SOBCZAK-KUPIEC, et al., 2011). During the synthesis at different concentrations, the sample color can change from yellow to brown to dark green. The changes in color can also be linked to the shape of the NPs (LIZ-MARZÁN, 2006).

A)

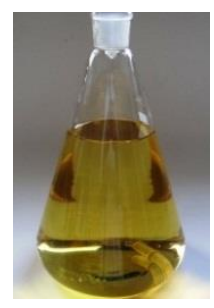

B)

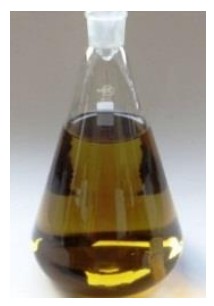

C)

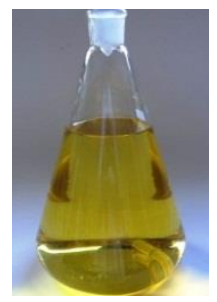

D)

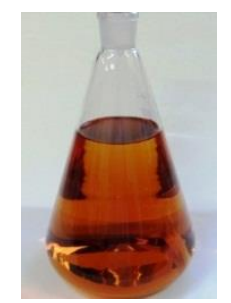

Figure 4: Visual results of the four studied synthesis routes I (A), II (B), III, (C) and IV (D).

\subsection{Treatment by EC}

The initial procedure to verify the applicability of the treatment by EC was conducted by monitoring the plasmon resonance spectrum of the solutions during the treatment time, which is the primary parameter that indicates the removal of the NPs from the solution and the efficiency. Figure 5 shows the variations of the absorption peaks for each studied route, which was obtained from the absorption spectrum of each point during EC until the moment when the recorded intensity was less the detection limit of the device (0.001 AU). This limit was established by a dilution assay using commercial 
standard aqueous solutions with sizes $10 \pm 4 \mathrm{~nm}, 20 \pm 4 \mathrm{~nm}$, and $40 \pm 4 \mathrm{~nm}$ (Sigma-Aldrich) and a concentration of $0.02 \mathrm{mg} / \mathrm{mL}( \pm 5 \%)$.

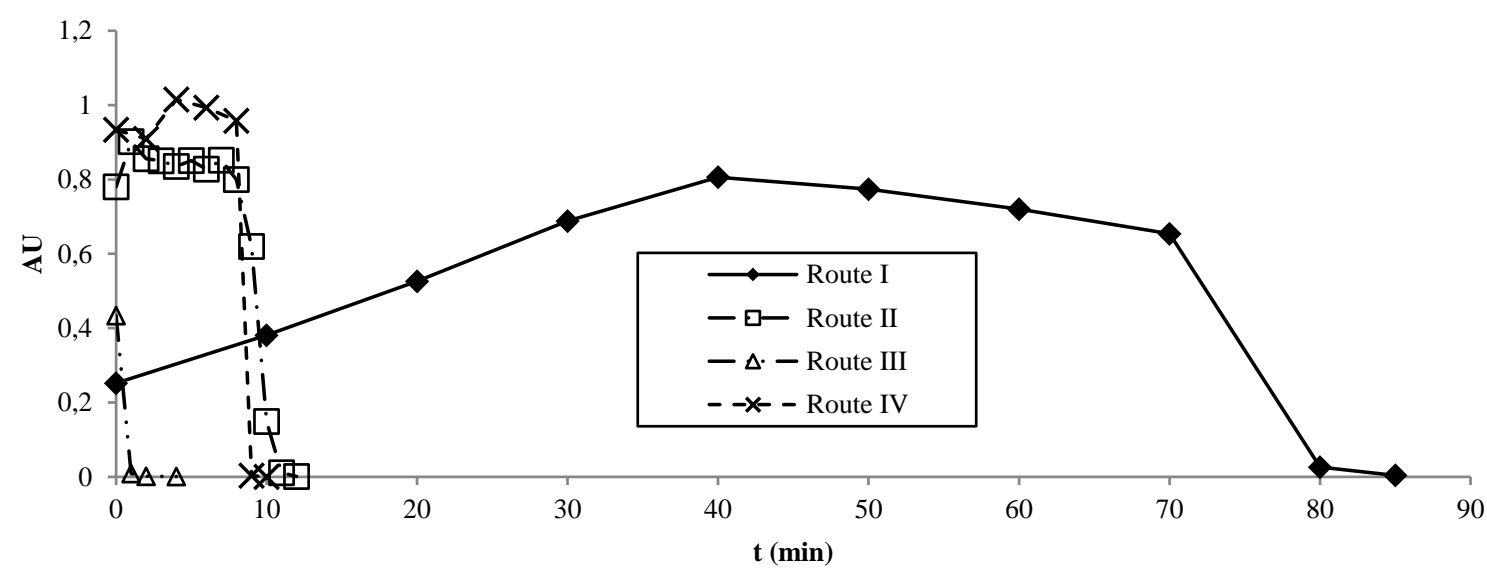

Figure 5: Variation of the UV/VIS absorption peak for each studied route during the EC process (applied current of 0.3 A for Route I and II and 0.2 A for Route III and IV).

In this sense, in the initial analysis of route $\mathrm{I}$, a current of $0.3 \mathrm{~A}$ was applied for 85 minutes until the detection limit of the device was reached. For this route, only after 85 minutes of treatment was there a significant decrease in the plasmon resonance peak of the sample, i.e., the decrease in the concentration of AgNP was $98.57 \%$.

It was also possible to record three behaviors in this scenario: an increase of the UV/Vis absorbance peak of the sample, the visible absence of insoluble $\mathrm{Al}(\mathrm{OH})_{3}$ in the solution after 70 minutes of treatment, and the formation of a precipitate on the anode of the electrolytic cell. The absence of flocs and consequently, of the production of $\mathrm{Al}(\mathrm{OH})_{3}$ after 70 minutes of treatment, can be explained by the solubility curve shown in Figure 6.

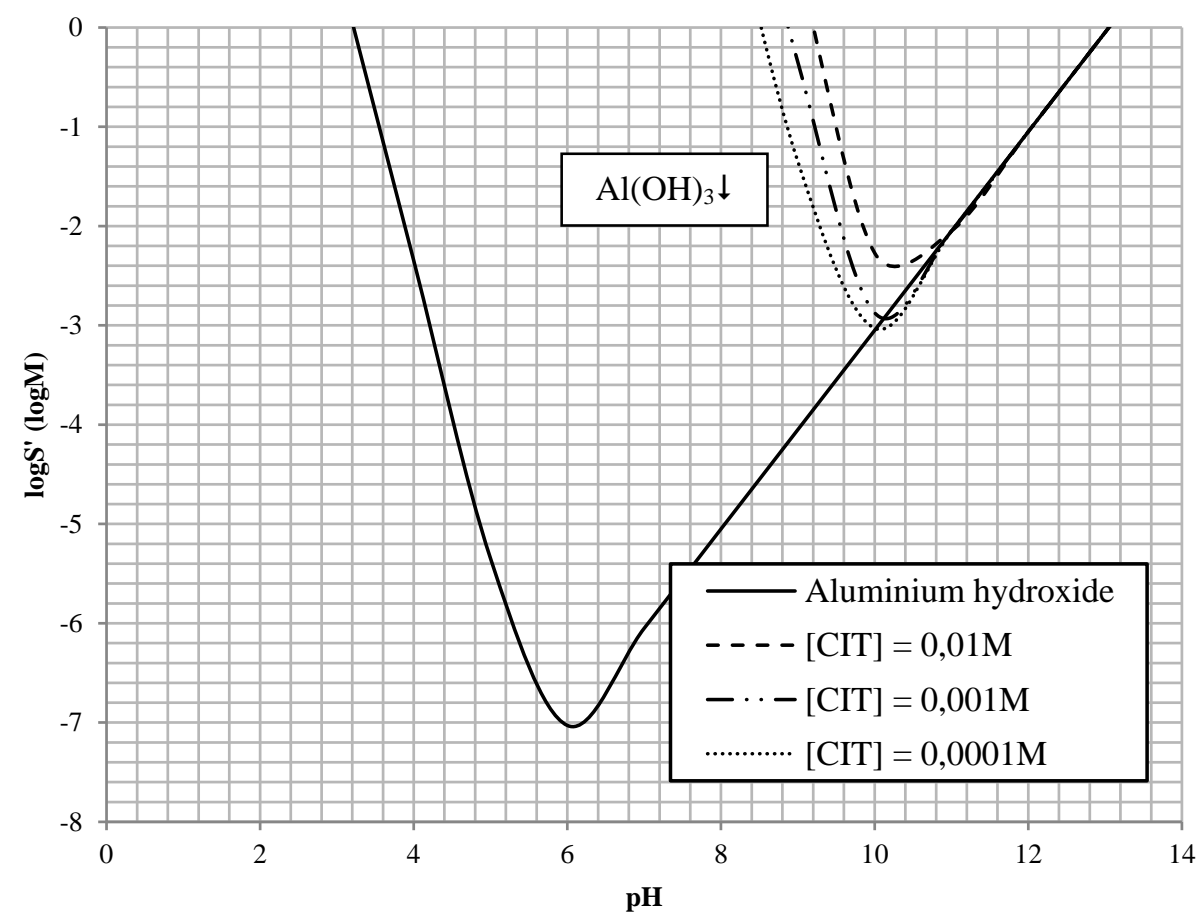

Figure 6: Conditional solubility curve (S') of the $\mathrm{Al}(\mathrm{OH}) 3$ in the presence of citrate. 
The curves shown in Figure 6 were obtained through Equation 4, Equation 5, Equation 6 and Equation 7:

$$
\log \mathrm{S}^{\prime}=\{\mathrm{z} \cdot[14-(\mathrm{pKs} / z)-\mathrm{pH}]\}+\log \alpha \mathrm{Al}(\mathrm{OH}, \mathrm{CIT})
$$

Equation 4

where $\mathrm{S}^{\prime}$ is conditional solubility of the aluminum hydroxide as a function of $\mathrm{pH}$ and in the presence of citrate $(\mathrm{mol} / \mathrm{L}), \mathrm{z}$ is valence of the ionic species of aluminum, $\mathrm{pKs}$ is solubility product of the aluminum hydroxide. For this parameter, the adopted value was 32.35 (POURBAIX, 1963) and_log $\alpha$ (Al(OH),CIT) is complexation coefficient of the ionic aluminum in the presence of citrate and hydroxyl.

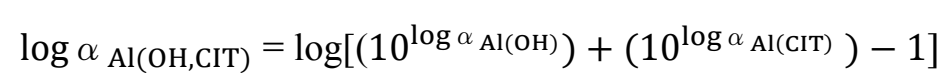

Equation 5

where $\log \alpha \mathrm{Al}(\mathrm{OH})$ is complexation coefficient of the ionic aluminum in the presence of hydroxyl and $\log \alpha$ CIT is complexation coefficient of the ionic aluminum in the presence of citrate.

$$
\alpha_{\mathrm{Al}(\mathrm{OH})}=1+\left(10^{\beta_{4}}\right) \cdot\left(10^{-14} / 10^{-\mathrm{pH}}\right)
$$

Equation 6

where $\beta_{4}$ is the formation constant of complexes of ionic aluminum with the hydroxyl ion. For this parameter, the adopted value was 33.3 (RINGBOM, 1963).

$$
\log \alpha_{\mathrm{Al}(\mathrm{CIT})}=1+\left(10^{\beta_{1}}\right) \cdot\left([\mathrm{CIT}] / 10^{\left.\log \alpha_{\mathrm{CIT}(\mathrm{H})}\right)}\right.
$$

Equation 7

where $\beta_{1}$ is formation constant of complexes of ionic aluminum with citrate anion $\left[\mathrm{O}-\mathrm{C}\left(\mathrm{CO}_{2}\right)-\left(\mathrm{CH}_{2}-\right.\right.$ $\left.\left.\mathrm{CO}_{2}\right)_{2}\right]^{4-}$. For this parameter, the adopted value was 20.0 (RINGBOM, 1963), [CIT] is citrate concentration $\left(\mathrm{mol} . \mathrm{L}^{-1}\right) ; \log \alpha \mathrm{CIT}(\mathrm{H})$ is protonation coefficient of citrate.

The adopted values for $\log \alpha \operatorname{CIT(H)}$ were extracted according to Table 3:

Table 3: Protonation coefficients of the citrate $\left(\log \alpha_{C I T(H)}\right)$ according to the $\mathrm{pH}$ of the medium (RINGBOM, 1963).

\begin{tabular}{lccccccccccccccc}
\hline $\mathbf{p H}$ & $\mathbf{0}$ & $\mathbf{1}$ & $\mathbf{2}$ & $\mathbf{3}$ & $\mathbf{4}$ & $\mathbf{5}$ & $\mathbf{6}$ & $\mathbf{7}$ & $\mathbf{8}$ & $\mathbf{9}$ & $\mathbf{1 0}$ & $\mathbf{1 1}$ & $\mathbf{1 2}$ & $\mathbf{1 3}$ & $\mathbf{1 4}$ \\
\hline $\log \boldsymbol{\alpha}_{\mathrm{CIT}(\mathrm{H})}$ & 13.5 & 10.5 & 7.5 & 4.8 & 2.7 & 1.2 & 0.25 & 0.05 & 0 & 0 & 0 & 0 & 0 & 0 & 0 \\
\hline
\end{tabular}

This curve shows that in the presence of citrate, the formation of aluminum hydroxide in an aqueous medium is modified. In other words, taking into account the $3 \mathrm{mM}$ concentration of sodium citrate, which is the same concentration used in synthetic route I, it can be concluded that precipitation of aluminum hydroxide occurs at a high $\mathrm{pH}(\mathrm{pH} \approx 10)$ only in higher aluminum concentrations with respect to the medium in the absence of citrate. This result means that precipitation only occurs once citrate is completely consumed by its complexation with aluminum. In this sense, the formation of flocs and the efficiency of elimination of NPs are linked to the duration of the treatment, to the amount of $\mathrm{Al}^{3+}$ produced by the anode, the $\mathrm{pH}$, and the citrate concentration.

A significant amount of precipitate fixed to the anode was also observed during treatment, which indicates a tendency for the occurrence of a phenomenon similar to anodization. This tendency leads to the significant increase in the potential difference at the end of the assay, which reflects strong energy consumption during treatment, i.e., $8.0 \times 10^{5} \mathrm{~J}$ (Equation 1).

It was not possible to verify the molecular structure of this precipitate with precision; however, its EDS analysis (Figure 7) confirmed the presence of aluminum and oxygen with a mass percentage of $23.15 \%$ and $61.86 \%$, respectively, which may indicate the precipitation of $\mathrm{Al}(\mathrm{OH})_{3}$ on the anode with respect to the molar ratio between the aluminum and oxygen of this species. Another hypothesis to be confirmed is the possibility of the formation of polymeric species along the electrode. This observation raises another problem in the treatment of AgNPs by EC: the difficulty in maintaining the chemical species of aluminum in solutions. 


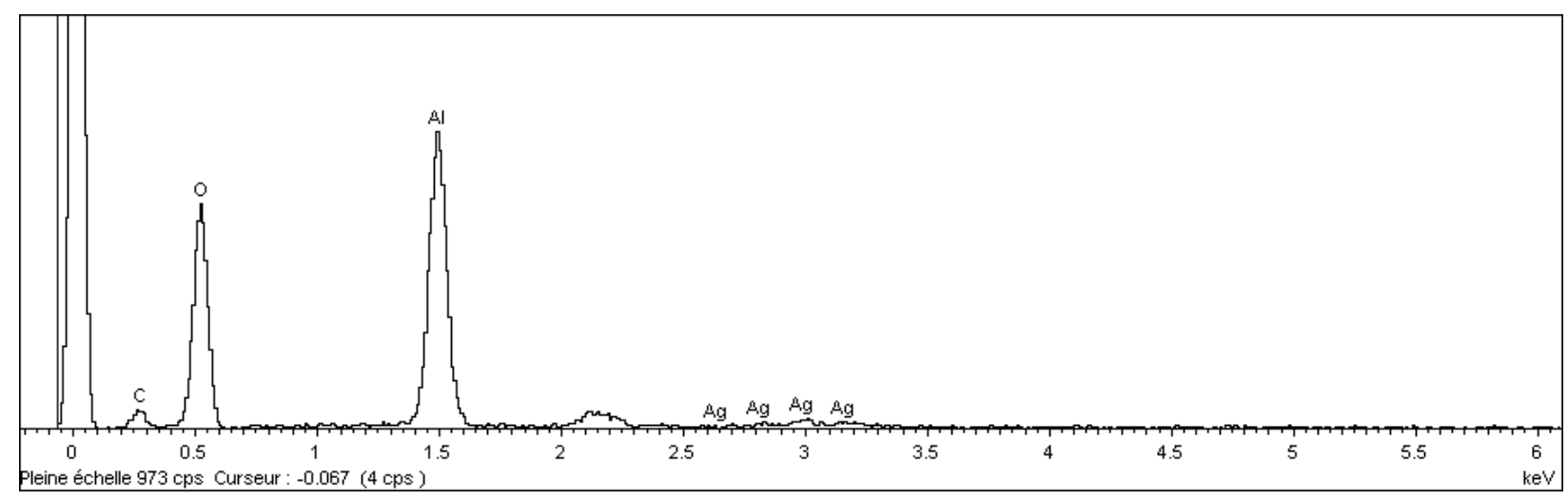

Figure 7: EDS spectrum of the precipitate collected at the anode of the electrolytic cell used to verify the efficiency of the EC process in route $I$.

In general, the most important result in the EC of route I in the citrate medium was the increase in the UV/Vis spectrum absorbance in the typical colloidal silver plasmon absorption band, which indicates possible formations of new NPs in the medium. This hypothesis was further investigated in an isolated assay where the same concentrations of sodium citrate dihydrate, silver nitrate, and sodium nitrate used in route I were used, which proceeded EC of the solution for 20 minutes at an intensity of $0.3 \mathrm{~A}$. The result of this assay is shown in Figure 8, where there is a peak at $430 \mathrm{~nm}$ and an absorbance of $0.780 \mathrm{AU}$, which indicates possible formation of silver particles.

A)

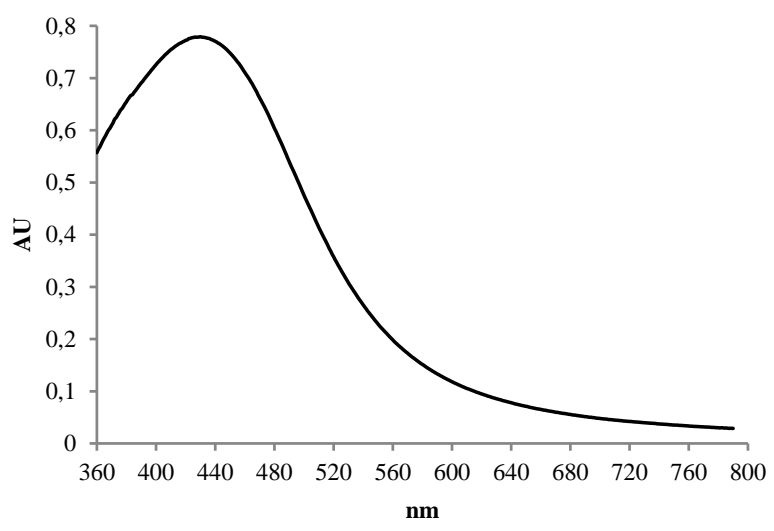

B)

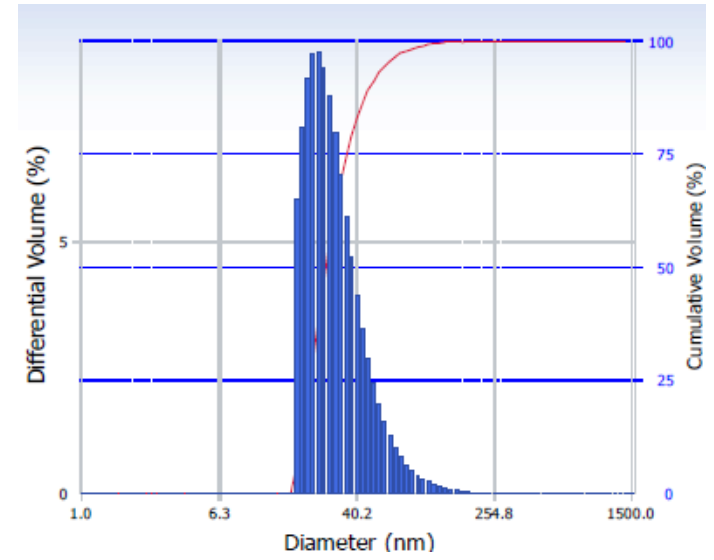

Figure 8: Result of the plasmon resonance spectrum (A) and DLS spectrum (B) to confirm the production of AgNPs by EC using the mass ratios and reagents of route $I$.

To confirm the obtained particle sizes, the DLS analysis showed through a differential volumetric analysis, a hydrodynamic diameter of less $50 \mathrm{~nm}$ (Figure 8B) and a PI of 0.309 . Thus, also considering that this diameter is a combined thickness with the stabilizing agent, the possibility of producing NPs during EC may be indicated; however, these results must be further investigated.

Following the same principle presented for route I, the observation of the behavior of the treatment by EC and the variation of the plasmon resonance spectrum over time for route II are also important. The obtained results showed that the precipitation of $\mathrm{Al}(\mathrm{OH})_{3}$ was observed in shorter treatment times due to the reduced concentration of sodium citrate dihydrate $(0.25 \mathrm{mM})$ compared with the previously discussed results. In this scenario, it was possible to observe the formation of flocs, which was translated by the precipitation of $\mathrm{Al}(\mathrm{OH})_{3}$ and followed by flotation. The theory explains why the hydrogen gas micro-bubbles that are produced at the cathode join the agglomerates, which causes the flotation of the suspended particles and forms sludge during the process (BARBOSA \& TERAN, 2009). It is noteworthy that electroflotation is also favored by smaller distances between the electrodes due to the upward movement of hydrogen gas (BARBOSA \& TERAN, 2009).

When applying a current of $0.3 \mathrm{~A}$, it was possible to observe that after 8 minutes of treatment, the plasmon band already exhibited a $20.5 \%$ decrease. After 12 minutes, the results reached values below the detection limit of the spectrometer, which indicated a decrease of at least $99.87 \%$ of AgNPs (Table 5) with an energy consumption of $3.0 \times 10^{3} \mathrm{~J}$ (Equation 1). 
The results obtained in the EC of route III were significantly different from the previously discussed results. This route, despite showing an important temporal stability (Figure 2C), in less than 1 minute of treatment, already exhibited a reduction greater than $97 \%$. This behavior can be explained by the low zeta potential recorded for route III, and hence, the tendency to for rapid destabilization and the precipitation of NPs, which is primarily attributed to the change in the ionic force of the medium with the presence of sodium nitrate added to ensure the medium conductivity. After more than 4 minutes of treatment (Table 5) and applying a current of $0.2 \mathrm{~A}$, the absorbance intensities reached the uncertainty levels regarding the true concentration in NPs in the solution. There was a minimum reduction of $99.77 \%$ in this scenario.

Following the procedure adopted in the EC treatment of the previously presented routes, the UV/Vis absorption spectrum was monitored again; this time, using a 10-minute treatment for route IV and applying a current of $0.2 \mathrm{~A}$, it was possible to identify the rapid drop of the UV/Vis absorption peak between 8 and 9 minutes of treatment, which represents a decrease of 99.69\% in terms of mass of AgNPs. A value of zero was finally reached in the typical plasmon resonance band of AgNPs at the end of the treatment, which results in a reduction rate of the minimum absorbance of $99.89 \%$. Table 4 summarizes the main results obtained throughout the treatment by EC:

Table 4: EC results obtained from the four researched synthetic routes.

\begin{tabular}{|c|c|c|c|c|c|c|c|}
\hline Routes & & & & I & II & III & IV \\
\hline Time & $(\min )$ & & & 85 & 12 & 4 & 10 \\
\hline \multirow{2}{*}{$\begin{array}{l}\text { Current } \\
\text { intensity }\end{array}$} & \multirow{2}{*}{\multicolumn{2}{|c|}{ (A) }} & ${ }^{1}$ Ini. & 0.3 & 0.3 & 0.2 & 0.2 \\
\hline & & & ${ }^{2}$ Fin. & 0.3 & 0.3 & 0.2 & 0.2 \\
\hline \multirow{2}{*}{ Voltage } & \multirow{2}{*}{\multicolumn{2}{|c|}{$(V)$}} & ${ }^{1}$ Ini. & 16 & 40 & 21 & 22 \\
\hline & & & ${ }^{2}$ Fin. & 200 & 38 & 23 & 23 \\
\hline \multirow{2}{*}{ pH } & \multirow{2}{*}{\multicolumn{2}{|c|}{-}} & ${ }^{1}$ Ini. & 7.0 & 6.1 & 5.6 & 7.5 \\
\hline & & & ${ }^{2}$ Fin. & 8.6 & 8.6 & 7.5 & 8.7 \\
\hline \multirow{2}{*}{ Conductivity } & \multirow{2}{*}{\multicolumn{2}{|c|}{$(\mu \mathrm{S} / \mathrm{cm})$}} & ${ }^{1}$ Ini. & 1078 & 487 & 495 & 521 \\
\hline & & & ${ }^{2}$ Fin. & 860 & 453 & 469 & 520 \\
\hline \multirow{4}{*}{${ }^{3}$ Absorbance } & \multirow{2}{*}{$\lambda \max$} & \multirow{2}{*}{$(n m)$} & Ini. & 423 & 395 & 405 & 401 \\
\hline & & & ${ }^{2}$ Fin. & 417 & 408 & 438 & 407 \\
\hline & \multirow{2}{*}{ Abs } & \multirow{2}{*}{ (u.a.) } & Ini. & 0.252 & 0.780 & 0.434 & 0.934 \\
\hline & & & ${ }^{2}$ Fin. & 0.004 & 0.001 & 0.001 & 0.001 \\
\hline
\end{tabular}

Table 5 presents parameters, such as the current density (Equation 2), to establish a pattern in comparative terms between the routes, final treatment time, consumed energy (Equation 1), and the relative removal efficiency between the intensity of the initial and final absorption peaks. The heterogeneous character of the behavior of AgNP treatment by EC is thus confirmed.

Despite we employed Faraday's Law, the results of electrode mass consumption need to be analyzed with caution. Studies have shown that the mass consumption in an EC process using aluminum electrodes is not only due to the electrochemical reaction explained by this law, but also by a chemical reaction that results in the dissolution of the cathode (PICARD, et al., 2000) (KHALED, et al., 2015), which has yet to be fully clarified. With this, we choose denominated the mass consumption of electrode as partial, disregarding the chemical dissolution of the cathode, and the results can be analyzed with data obtained exclusively from Equation 3.

Route I showed $96.86 \%$ of mass consumption exceeds the Route II. Route II and III showed mass consumption, respectively, $85.88 \%$ and $92.16 \%$ below the Route I, mainly due to the exposure time of the electrode to the EC process. Importantly, this evaluation cannot be performed compared to other EC processes using other metal.

In the financial analysis of the treatment cost, attend initially the energy consumption, considering the average cost of 12.81 cents / $\mathrm{kWh}$ according to the International Energy Agency, the value of treatment by EC presented a variation between 0.015 and 1.373 cents / L. Similarly, if we combine the 
energy cost to the partial mass cost (disregard the mass consumption of the cathode by chemical dissolution) of aluminum, where the mean value adopted of aluminum was 1,845.91 US \$/ton according to the London Metal Exchange, the variation of total cost per liter will be between 0.02 and 1.50 cents / L.

Table 5: Summary of results obtained through the treatment of AgNPs by EC.

\begin{tabular}{|c|c|c|c|c|c|c|c|}
\hline & $\begin{array}{l}\text { Current } \\
\text { density }\end{array}$ & $\begin{array}{l}\text { Treatment } \\
\text { time }\end{array}$ & $\begin{array}{l}\text { Consumed } \\
\text { energy }\end{array}$ & $\begin{array}{c}\text { Parcial } \\
\text { electrodes } \\
\text { mass } \\
\text { consumption } 1 \\
(m g / L)\end{array}$ & $\begin{array}{c}\text { Relative } \\
\text { removal } \\
\text { efficiency } \\
(\%)\end{array}$ & $\begin{array}{c}\text { Energy } \\
\text { cost }^{2}\end{array}$ & $\begin{array}{c}\text { Cost of } \\
\text { aluminum }^{3}\end{array}$ \\
\hline Route I & 89.8 & 85 & 96480.00 & 713.10 & 98.57 & 1.373 & 0.132 \\
\hline Route II & 89.8 & 12 & 7524.00 & 100.67 & 99.87 & 0.107 & 0.019 \\
\hline Route III & 59.9 & 4 & 1080.00 & 22.37 & 99.77 & 0.015 & 0.004 \\
\hline Route IV & 59.9 & 10 & 2712.00 & 55.93 & 99.89 & 0.039 & 0.010 \\
\hline
\end{tabular}

1: mass electrode consumption (mg) compared to the treated volume (L); it has disregarding chemical dissolution of the cathode.

2: average yearly cost of energy, according to International Energy Agency.

3: aluminum cost according to the London Metal Exchange annual average.

\subsubsection{Influence of reagents}

To verify the interference by reagents in the EC process, tests were conducted to identify the influence of D-glucose, sodium citrate, and sodium pyrophosphate on the obtained treatment results.

The first test used synthesis route IV in the presence of D-Glucose $(1.6 \mathrm{mM})$ to estimate the possible interference of this reagent in eliminating AgNPs from the solution. It can be observed in Figure 9A that the presence of D-Glucose has a tendency to reduce the EC treatment time. This result may explain the rapid decrease of the plasmon resonance peak that was verified in the first four minutes of treatment of route III compared with the treatment of routes II and V. This leads to the hypothesis that Dglucose may undergo some type of polymerization during the EC process, which favors the formation of flocs; however, this conclusion requires further studies.

A)

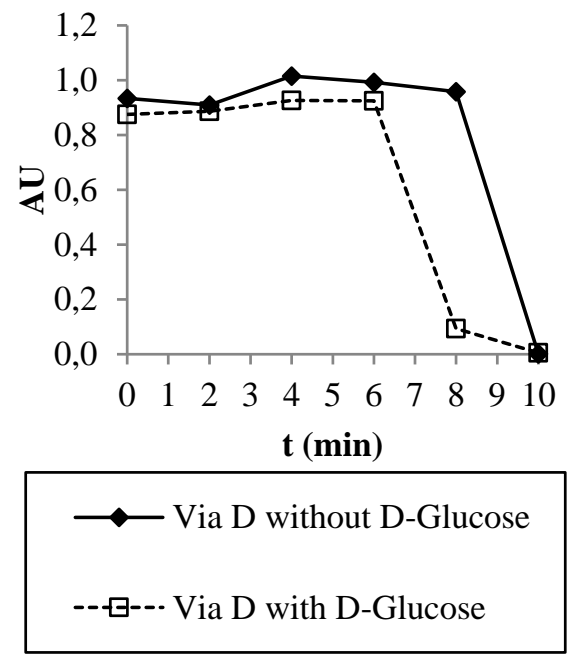

B)
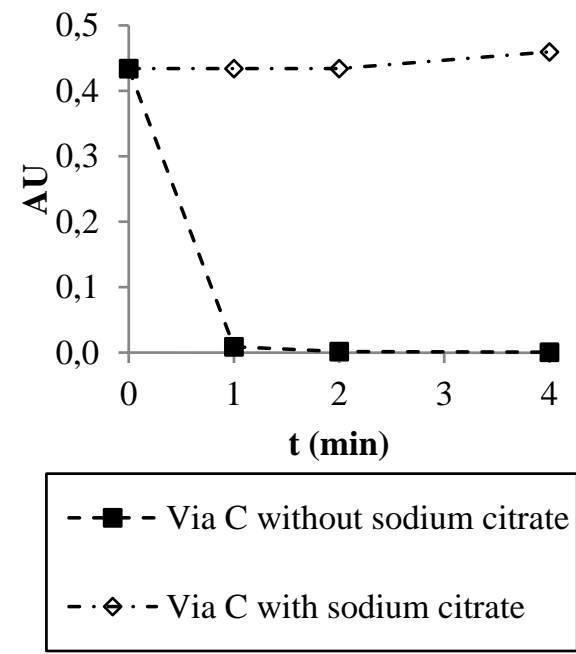

C)

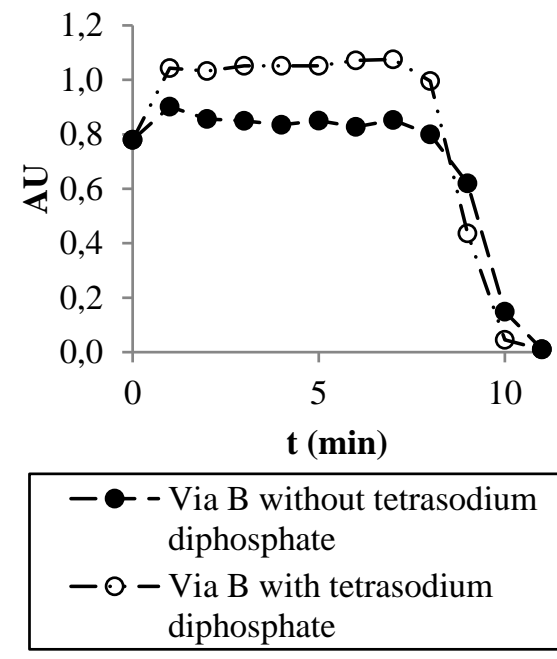

Figure 9: Influence of D-glucose (A), sodium citrate (B), and sodium pyrophosphate (C) in the treatment of AgNPs by EC.

The goal of the second test was to verify the interference of the sodium citrate in the solutions. Therefore, a comparative study of the EC of the solution synthesized by route III in the presence and absence of sodium citrate at a concentration of $5 \mathrm{mM}$ was conducted. Figure 9B shows the influence of the treatment in the presence of sodium citrate. There was no reduction of the UV/Vis absorbance peak of 
the sample containing this compound during the 4 minutes of treatment, which confirms its negative influence on the EC treatment.

The last test measured the interference of sodium pyrophosphate in the EC treatment. When comparing the electrolysis of the synthesized solution by route II in the presence and absence of sodium pyrophosphate decahydrate $(0.025 \mathrm{mM})$, it can be observed in Figure $9 \mathrm{C}$ that an increase in the plasmon resonance peak occurred between 0 and 7 minutes of treatment in the presence of pyrophosphate followed by a slightly more rapid drop after 9 minutes. Statistically, using the ANOVA method, it can only be stated that the presence of sodium citrate influences the treatment with a p-value of 0.050 ; the other scenarios resulted in p-values of to 0.470 (Figure 9A) and 0.520 (Figure 9C). This method ensures the statistical influence of the studied factors only in cases where the p-value is equal or less than 0.05.

\section{Conclusions and recommendations}

The results obtained showed variations under different synthesis conditions, which confirm the application for effluent treatment containing AgNPs by EC. The medium containing NPs was found to directly influence the treatment results, and solutions containing sodium citrate considerably changed the time required to eliminate AgNPs from the synthesized effluent, whereas solutions free of this substance exhibited the best scenario for the formation of flocs and therefore, represent the best treatment.

Under conditions where the solutions contained sodium citrate, it was possible to verify the importance of the optimal EC time; otherwise, there is a likely increase of AgNPs in the treated solution. The results showed an increase in the peak absorbance in the UV/Vis spectrum of solutions that underwent EC.

With regard to economic and financial analysis of EC process for removing AgNPs, a data collection is required in respect to the mass consumption to be performed by electrodes weighing before and after EC. Only in this way you can check real value of the cost of the operation on its raw material, and provides data that can be effectively compared with other processes. It is suggested for future research, in addition of analysis of this parameter, the monitoring of sludge formed after EC. It is understood that the amount of sludge generated in the wastewater treatment process is a major liability in the management of Wastewater Treatment Plants. Additionally to its volume, its toxicity should be studied to be defined how best to its final disposal or valuation in other processes.

With regard to the synthesis of AgNPs in an aqueous medium, this is a particularly simple technique, though much care is to be used to maintain the purity of the solvent and reagents, the properties of the glassware used, temperature conditions, and the synthesis time for its correct stabilization.

Finally, understanding several interfering variables during the EC process allowed for the identification of the applicability of this treatment technique on AgNPs. It is important to verify its efficiency under other nanometric suspensions, study different flow regimes, and study its behavior at larger treatment scales to consolidate this nanoscience technology.

\section{Acknowledgements}

To École Nationale Supérieure de Chimie de Rennes, Université de Rennes 1 and Ecole des Metiers de l'Environnement, and all their outstanding professors. To Coordenação de Aperfeiçoamento de Pessoal de Nível Superior (CAPES) that provided this study mission.

\section{References}

BARBOSA, I. M. \& TERAN, F. J. C., 2009. Eletrocoagulation-flotation applied to the treatment of wastewater gerated in plastic recycling industry. Holos Environment, 9(1), pp. 93-112.

BONIFÁCIO, L. S., 2006. Processos de agregação e fusão de nanopartículas de ouro: Uma abordagem química. Universidade de São Paulo, pp. 1-116.

CHANDINI, ANDHARIYA, N., PANDEY, O. \& CHUDASAMA, B., 2013. A growth kinetic study of ultrafine monodispersed silver nanoparticles. RSC Advances, Volume 3, pp. 1127-1136.

CHOI, O., DENG, K. K. \& HU, Z., 2008. The inhibitory effects of silver nanoparticles, silver ions, and silver chloride colloids on microbial growth. Water Research, 42(12), pp. 3066-3074. 
CLESCERI, L. S., GREENBERG, A. E. \& EATON A. D., eds., 1998. Standard methods for the examination of water and wastewater. 20 ed. Washington, D.C.: American Public Health Association.

CUMBERLAND, S. A. \& LEAD, J. R., 2009. Particle size distributions of silver nanoparticles at environmentally relevant conditions. Journal of Chromatography A, 1216(52), pp. 9099-9105.

DENG, Y., SUN, Y. \& ZHANG, D., 2008. Nonlinear optical properties of silver colloidal solution by in situ synthesis technique. Current Applied Physics, 8(1), pp. 13-17.

DUQUET, D., TROTTIER, E. \& CARTER, D., 2006. Éthique et nanotechnologies, se donner les moyens d'agir (Avis). Québéc: Commission de l'Éthique de la Science et de la Technologie.

HEIDMANN, I. \& CALMANO, W., 2008. Removal of $\mathrm{Zn}(\mathrm{II}), \mathrm{Cu}(\mathrm{II}), \mathrm{Ni}(\mathrm{II}), \mathrm{Ag}(\mathrm{I})$ and $\mathrm{Cr}(\mathrm{VI})$ present in aqueous solutions by aluminium electrocoagulation. Journal of Hazardous Materials, 152(3), p. 934-941.

HOU, L. et al., 2013. Removal of silver nanoparticles in simulated wastewater treatment processes and its impact on COD and NH4 reduction. Chemosphere, 87(3), pp. 248-252.

JEONG, E. et al., 2014. Different susceptibilities of bacterial community to silver nanoparticles in wastewater treatment systems. Journal of Environmental Science and Health - Part A Toxic/Hazardous Substances and Environmental Engineering, 49(6), pp. 685-693.

KAEGI, R. et al., 2011. Behavior of metallic silver nanoparticles in a pilot wastewater treatment plant. Environmental Science and Technology, 45(9), pp. 3902-3908.

KANG, B.-K., SON, D.-M. \& KIM, Y., 2011. Preparation and characterization of silver nanoparticles embedded in silica sol particles. Bulletin of the Korean Chemical Society, 32(10), pp. 3707-3711.

KHALED, B. et al., 2015. Investigation of electrocoagulation reactor design parameters effect on the removal of cadmium from synthetic and phosphate industrial wastewater. Arabian Journal of Chemistry.

KHANDEGAR, V. \& SAROHA, A. K., 2013. Electrocoagulation for the treatment of textile industry effluent - A review. Journal of Environmental Management, Volume 128, p. 949-963.

KHAN, M. A. M., KUMAR, S. \& ALDWAYYAN, A. S., 2011. Structural and spectroscopic studies of thin film of silver nanoparticles. Applied Surface Science, 257(24), pp. 10607-10612.

KHAN, S. S., MUKHERJEE, A. \& CHANDRASEKARAN, N., 2012. Adsorptive removal of silver nanoparticles (SNPs) from aqueous solution by Aeromonas punctata and its adsorption isotherm and kinetics. Colloids and Surfaces B: Biointerfaces, Volume 92, pp. 156-160.

KHEYBARI, S., SAMADI, N. \& FAZELI, M. R., 2010. Synthesis and antimicrobial effects of silver nanoparticles produced by chemical reduction method. Journal of Pharmaceutical Sciences, 18(3), pp. 168-172.

KHOLOUD, M. M., ABOU, E.-N. \& ALA`A, E., 2010. Synthesis and applications of silver nanoparticles. Arabian Journal of Chemistry, 3(3), pp. 135-140.

KRUTYAKOV, Y. A., KUDRINSKIY, A. A. \& LISICHKIN, G. V., 2008. Synthesis and properties of silver nanoparticles: advances and prospects. Russian Academy of Sciences and Turpion, March, 77(3), pp. 233-257.

LIZ-MARZÁN, L., 2006. Tailoring surface plasmons through the morphology and assembly of metal nanoparticles. Langmuir, 22(1), pp. 32-41.

LU, J. et al., 2015. Removing heavy metal ions with continuous aluminum electrocoagulation: A study on back mixing and utilization rate of electro-generated Al ions. Chemical Engineering Journal, Volume 267, p. 86-92.

MOLLAH, M. Y., SCHENNACH, R. \& COCKE, D. L., 2001. Electrocoagulation (EC) - science and applications. Journal of Hazardous Materials, 84(1), pp. $29-41$.

NETO, E. A. B., RIBEIRO, C. \& ZUCOLOTTO, V., 2010. Desenvolvimento de nanobiocompósitos contendo nanopartículas de prata para aplicações bactericidas. Universidade de São Paulo, Junho.pp. 1-112.

PICARD, T., CATHALIFAUD-FEUILLADE, G., MAZET, M. \& VANDENSTEENDAM, C., 2000. Cathodic dissolution in the electrocoagulation process using aluminium electrodes. Journal of Environmental Monitoring, February, 2(1), pp. 77-80.

PINTO, V. V., FERREIRA, M. J. \& PEREIRA, C. M., 2010. Long time effect on the stability of silver nanoparticles in aqueous medium: Effect of the synthesis and storage conditions. Colloids and Surfaces A: Physicochemical and Engineering Aspects, 364(1-3), pp. 19-25.

POURBAIX, M., 1963. Atlas d'equilibres electrochimiques. Paris: Gauthier-Villars.

RINGBOM, A., 1963. Complexation in analytical chemistry. New York: Interscience Publishers.

SELLERS, K., MACKAY, C. \& HAMBELN, J., 2009. Nanotechnology and the environment. Boca Raton: CRC Press.

SHI, Y., QI, Z. \& WANG, H., 2011. A facile method for the synthesis of silver nanoparticles in the presence of sodium phosphate. Applied Mechanics and Materials, 109(2012), pp. 174-177.

SILVA, A. A. R., 2009. Avaliação das técnicas de eletrocoagulação e eletroflotação na recuperação de efluentes de lavagem de veículos. Universidade Estadual de Londrina, March.pp. 1-101. 
SOBCZAK-KUPIEC, A., MALINA, D. \& ZIMOWSKA, M., 2011. Influence of silver nitrate concentration on the properties of silver nanoparticles. Micro and Nano Letters, 6(8), pp. 656-660.

SUN, Q. et al., 2013. Removal of silver nanoparticles by coagulation processes. Journal of Hazardous Materials, Volume 261, pp. 414-420.

TRÉMILLON, B. \& DURAND, G., 1999. Électrochimie - Préliminaires à l'étude de l'électrolyse. Techniques de l'Ingénieur, September.pp. 1-19.

YANG, Y. et al., 2014. Pyrosequencing reveals higher impact of silver nanoparticles than Ag+ on the microbial community structure of activated sludge. Water Research, Volume 48, pp. 317-325. 